\title{
A Comparative Analysis of the Curve of Spee \\ (Lateral aspect) before and after \\ Orthodontic Treatment
}

-With Particular Reference to Overbite Patients-

\author{
by \\ Tetsu KOYAMA*

\section{Introduction}

A correct curve of Spee is requisite for an adequate retention following an orthodontic treatment but, in overbite patients, a pronounced degree of curve of Spee is rather frequently found.

In these process, we have recourse to the leveling procedure in an effort to reduce it.

In the present study, the author was concerned with, from a morphological point of view, a comparative analysis of curves of Spee before and after a dynamic orthodontic treatment by use of edgewise appliance to the overbite patients. At the same time, an effort was made to determine what kind of morphology and degree of it would operate in the stabilized occlusal relationship after retention.

\section{Material and Method}

By way of study material, a selective use was made of 20 overbite patients, who are generally considered to be intimately connected with the curve of Spee, from those treated in the Department of Orthodontics, Nihon University School of Dentistry, by means of edgewise applicances.

Their preoperative, postoperative and after retention models, 60 in total, were used for the present purpose.

As the criteria, the preoperative cases were selected as being over Hellman dental age $111 \mathrm{C}$, free from dental defects, fillings or any pernicious habit. As for the cases after dynamic treatment, those in whom the molar occlusal relationship, crowding of the anteriors and the degrees of overjet and overbite had been apparently improved, with no subsequent relapse after retention and in stablized occlusion, were selected. All the cases under study had their 4 first premolars extracted and their average age at the commencement of treatment was 13 years 11 months, it being 17 years 5 months at the conclusion of dynamic treatment. At the end of retention, their average age was 19 years 11 months.

The method of measurements followed that of KamATA, in which on the dental casts two planes: an occlusal plane linking the central incisal edge center with the

*小山 哲: Dept. of Orthodontics, Nihon University School of Dentistry, Tokyo (Director: Prof. Masatoshi Arita). 
disto-buccal cusp ridge of the first molars (1-6 o.p.) and another linking the central incisal edge center with the disto-buccal cusp ridge of the second molars (1-7 o.p.) were established both for the maxilla and the mandible.

The vertical distances from these planes to the incisal edge and cusp ridge were measured by use of a curve of Spee meter developed by our Department (Fig. 1). In preparing charts of the curve of Spee in this manner, a divider was used to measure the cusp ridge distances of respective incisal cusp ridges.

In measuring the degree of overbite, the maxillary casts were set in such a manner that the measuring apparatus would be in a horizontal position to the mandibular right and left central incisal edges as well as the right and left first molar disto-buccal cusp ridges in an effort to determine the degree of vertical covering on the part of maxillary and mandibular left central incisors (Fig. 2).

All the measurements were performed 3 times and their mean values were used for interpretation.
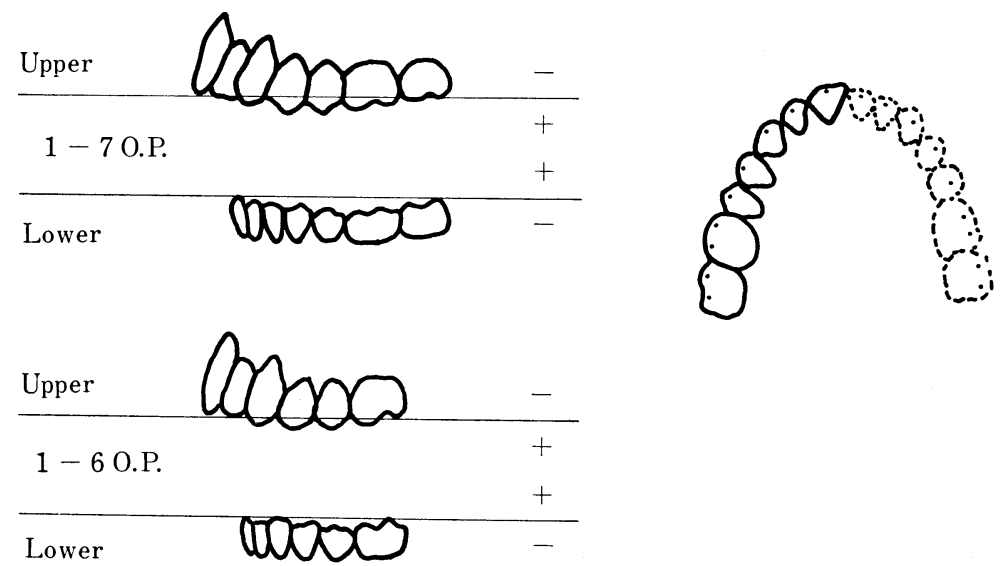

Fig. 1.
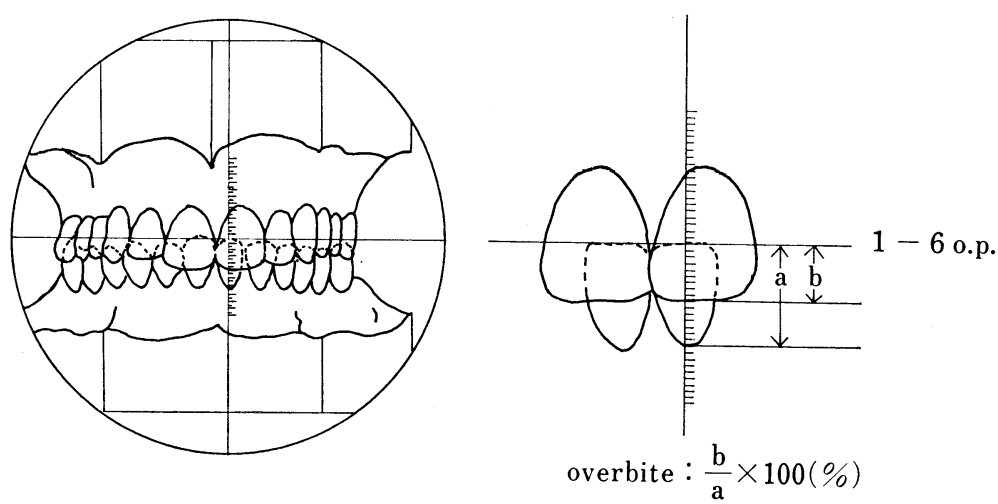

Fig. 2. 


\section{Findings}

1) The results of measurements of distances from the occlusal plane to incisal cusp ridges, cusp ridge intervals and degree of overbite preoperatively, postoperatively and after rentention are given in Tables 1 to 7 .

Table 1. Means and Standard Deviations of Distances of Edges and Molar Buccal Cusps to the Occlusal Surface (Preoperative)

\begin{tabular}{|c|c|c|c|c|c|c|c|c|c|}
\hline & & \multicolumn{4}{|c|}{ Right } & \multicolumn{4}{|c|}{ Left } \\
\hline & & \multicolumn{2}{|c|}{ Upper } & \multicolumn{2}{|c|}{ Lower } & \multicolumn{2}{|c|}{ Upper } & \multicolumn{2}{|c|}{ Lower } \\
\hline & & $\mathrm{M}$ & S.D. & M & S.D. & $\mathrm{M}$ & S.D. & M & S.D. \\
\hline \multirow{7}{*}{ 1-7 o.p. } & 2 & 0.79 & 1.33 & -0.25 & 0.56 & 0.53 & 0.97 & -0.22 & 0.59 \\
\hline & 3 & 0.87 & 0.89 & -0.76 & 0.85 & 0.97 & 0.96 & -0.75 & 0.75 \\
\hline & 4 & 2.40 & 0.80 & -2.44 & 0.98 & 2.26 & 1.16 & -2.14 & 0.84 \\
\hline & 5 & 2.82 & 1.28 & -3.69 & 1.50 & 3.07 & 1.48 & -3.31 & 1.30 \\
\hline & $6 n$ & 2.72 & 1.40 & -3.24 & 0.93 & 2.63 & 1.45 & -3.05 & 1.32 \\
\hline & 61 & 2.81 & 1. 36 & -2.54 & 0.70 & 2.53 & 1.47 & -2.35 & 0.71 \\
\hline & $7 \mathrm{n}$ & 1.24 & 0.90 & -1.28 & 0.37 & 0.84 & 0.85 & -1.20 & 0.50 \\
\hline \multirow{5}{*}{ 1-6 o.p. } & 2 & 0.47 & 0.85 & 0.02 & 0.52 & 0.47 & 0.78 & -0.11 & 0.58 \\
\hline & 3 & 0.03 & 1.58 & -0.21 & 0.71 & 0.51 & 0.93 & -0.56 & 0.90 \\
\hline & 4 & 1.11 & 0.79 & -1.35 & 1.02 & 1. 30 & 0.76 & -1.47 & 1.04 \\
\hline & 5 & 1.00 & 0.74 & -1.63 & 1.00 & 1.10 & 0.85 & -1.87 & 0.84 \\
\hline & $6 n$ & 0.26 & 0.42 & -0.91 & 0.54 & 0.38 & 0.62 & -1.07 & 0.47 \\
\hline
\end{tabular}

Table 2. Means and Standard Deviations of Distances of Edges and Molar Cusps to the Occlusal Surface (Postoperative)

\begin{tabular}{|c|c|c|c|c|c|c|c|c|c|}
\hline & & \multicolumn{4}{|c|}{ Right } & \multicolumn{4}{|c|}{ Left } \\
\hline & & \multicolumn{2}{|c|}{ Upper } & \multicolumn{2}{|c|}{ Lower } & \multicolumn{2}{|c|}{ Upper } & \multicolumn{2}{|c|}{ Lower } \\
\hline & & $\mathrm{M}$ & S.D. & $\mathrm{M}$ & S.D. & M & S.D. & $\mathrm{M}$ & S.D. \\
\hline \multirow{6}{*}{ 1-7 o.p. } & 2 & -0.71 & 0.68 & -0.22 & 0.90 & -0.34 & 0.58 & -0.22 & 0.33 \\
\hline & 3 & 0.02 & 1.13 & -0.06 & 0.63 & 0.10 & 0.93 & -0.21 & 0.57 \\
\hline & 5 & 0.28 & 0.81 & -0.68 & 0.73 & 0.59 & 0.97 & -1.11 & 0.88 \\
\hline & $6 n$ & 0.51 & 0.98 & -1.21 & 0.97 & 0.76 & 1.29 & -1.54 & 1.09 \\
\hline & 61 & 0.90 & 0.86 & -1.14 & 0.86 & 1.03 & 1.27 & -1.32 & 1.27 \\
\hline & $7 \mathrm{~m}$ & 0.56 & 0.70 & -0.53 & 0.44 & 0.50 & 0.54 & -0.59 & 0.55 \\
\hline \multirow{4}{*}{ 1-6 o.p. } & 2 & -0.58 & 0.59 & -0.08 & 0.46 & -0.43 & 0.64 & -0.04 & 0.33 \\
\hline & 3 & -0.10 & 0.98 & 0.30 & 0.50 & -0.12 & 0.95 & 0.12 & 0.38 \\
\hline & 5 & -0.19 & 0.82 & -0.13 & 0.57 & -0.06 & 0.75 & -0.45 & 0.52 \\
\hline & $6 n$ & -0.13 & 0.75 & -0.18 & 0.40 & -0.12 & 0.71 & -0.54 & 0.52 \\
\hline
\end{tabular}


Table 3. Means and Standard Deviations of Distances of Edges and Molar Cusps to the Occlusal Surface after Retention

\begin{tabular}{|c|c|c|c|c|c|c|c|c|c|}
\hline & & \multicolumn{4}{|c|}{ Right } & \multicolumn{4}{|c|}{ Left } \\
\hline & & \multicolumn{2}{|c|}{ Upper } & \multicolumn{2}{|c|}{ Lower } & \multicolumn{2}{|c|}{ Upper } & \multicolumn{2}{|c|}{ Lower } \\
\hline & & M & S.D. & M & S.D. & M & S.D. & M & S.D. \\
\hline \multirow{6}{*}{ 1-7 o.p. } & 2 & -0.61 & 0.67 & -0.16 & 0.31 & -0.57 & 0.51 & -0.24 & 0.30 \\
\hline & 3 & -0.11 & 0.77 & -0.11 & 0.59 & -0.17 & 0.69 & -0.34 & 0.28 \\
\hline & 5 & 0.06 & 0.58 & -0.93 & 0.83 & 0.10 & 0.78 & -1.27 & 0.71 \\
\hline & $6 \mathrm{n}$ & 0.19 & 0.70 & -1.24 & 0.79 & 0.34 & 0.90 & -1.79 & 0.87 \\
\hline & 61 & 0.68 & 0.83 & -1.02 & 0.75 & 0.74 & 0.81 & -1.32 & 0.81 \\
\hline & $2 n$ & 0.27 & 0.48 & -0.56 & 0.39 & 0.25 & 0.42 & -0.78 & 0.45 \\
\hline \multirow{4}{*}{ 1-6 o.p. } & 2 & -0.75 & 0.67 & -0.04 & 0.46 & -0.57 & 0.59 & -0.08 & 0.38 \\
\hline & 3 & -0.26 & 0.80 & 0.33 & 0.60 & -0.25 & 0.77 & 0.14 & 0.35 \\
\hline & 5 & -0.34 & 0.64 & -0.36 & 0.63 & -0.30 & 0.63 & -0.50 & 0.62 \\
\hline & $6 n$ & -0.32 & 0.46 & -0.34 & 0.29 & -0.30 & 0.24 & -0.62 & 0.41 \\
\hline
\end{tabular}

Table 4. Means and Standard Deviations of Edge Cusp Spaces (Preoperative)

\begin{tabular}{|c|c|c|c|c|c|c|c|c|c|c|}
\hline & \multicolumn{2}{|c|}{$1-1$} & \multicolumn{2}{|c|}{$1-2$} & \multicolumn{2}{|c|}{$2-3$} & \multicolumn{2}{|c|}{$3-4$} & \multicolumn{2}{|c|}{$4-5$} \\
\hline & $\mathbf{M}$ & S.D. & $\mathrm{M}$ & S.D. & M & S.D. & $\mathrm{M}$ & S.D. & M & S.D. \\
\hline \multirow{2}{*}{$\begin{array}{r}R \\
\text { Upper } \\
L\end{array}$} & \multirow{2}{*}{9.57} & \multirow{2}{*}{0.65} & 9.72 & 1.41 & 8.65 & 0.79 & 9.25 & 0.59 & 7.99 & 0.69 \\
\hline & & & 9.33 & 0.60 & 8.47 & 0.82 & 9.29 & 0.94 & 8.32 & 0.73 \\
\hline \multirow{4}{*}{$\begin{array}{r}\mathrm{R} \\
\text { Lower } \\
\mathrm{L}\end{array}$} & \multirow{2}{*}{6.03} & \multirow{2}{*}{0.42} & 6.45 & & 7.28 & 0.78 & 7.74 & 0.69 & 8.03 & 0.90 \\
\hline & & & 6.59 & 0.49 & 7.06 & 0.51 & 7.52 & 0.68 & 7.66 & 0.83 \\
\hline & \multicolumn{2}{|c|}{$5-6 n$} & \multicolumn{2}{|c|}{$6 n-61$} & \multicolumn{2}{|c|}{$61-7 . n$} & \multicolumn{2}{|c|}{$7 \mathrm{~m}-7 \mathrm{~d}$} & \multicolumn{2}{|c|}{ Total } \\
\hline & M & S.D. & M & S.D. & M & S.D. & M & S.D. & & \\
\hline \multirow{2}{*}{$\begin{array}{r}\mathrm{R} \\
\text { Upper } \\
\mathrm{L}\end{array}$} & 6.94 & 0.70 & 5.93 & 0.58 & 6.93 & 0.96 & 5.83 & 0.54 & \multirow{2}{*}{\multicolumn{2}{|c|}{131.84}} \\
\hline & 7.04 & 0.89 & 5.81 & 0.63 & 7.26 & 1.25 & 5.51 & 0.51 & & \\
\hline \multirow{2}{*}{$\begin{array}{r}\mathrm{R} \\
\text { Lower } \\
\mathrm{L}\end{array}$} & 7.71 & 1.29 & 5.21 & 0.53 & 7.76 & 0.95 & 4.85 & 0.45 & \multirow{2}{*}{\multicolumn{2}{|c|}{115.48}} \\
\hline & 7.62 & 0.96 & 5.12 & 0.58 & 7.90 & 1.13 & 4.95 & 0.74 & & \\
\hline
\end{tabular}


Table 5. Means and Standard Deviations of Edge Cusp Spaces (Postoperative)

\begin{tabular}{|c|c|c|c|c|c|c|c|c|c|c|}
\hline & \multicolumn{2}{|c|}{$1-1$} & \multicolumn{2}{|c|}{$1-2$} & \multicolumn{2}{|c|}{$2-3$} & \multicolumn{2}{|c|}{$3-5$} & \multicolumn{2}{|c|}{$5-6 n$} \\
\hline & M & S.D. & M & S.D. & M & S.D. & M & S.D. & M & S.D. \\
\hline \multirow{2}{*}{$\begin{array}{r}\mathrm{R} \\
\text { Upper } \\
\mathrm{L}\end{array}$} & \multirow{2}{*}{9.45} & \multirow{2}{*}{0.70} & 9.10 & 0.65 & 8.43 & 0.62 & 8.66 & 0.81 & 7.08 & 0.53 \\
\hline & & & 9.12 & 0.79 & 8.91 & 0.76 & 8.67 & 1.08 & 6.92 & 0.81 \\
\hline \multirow{4}{*}{$\begin{array}{r}\mathrm{R} \\
\text { Lower } \\
\mathrm{L}\end{array}$} & \multirow{2}{*}{6.15} & \multirow{2}{*}{0.48} & 6.61 & 0.60 & 7.22 & 0.54 & 7.83 & 0.62 & 7.33 & 0.81 \\
\hline & & & 6.51 & 0.35 & 7.28 & 0.50 & 7.35 & 0.49 & 7.57 & 0.64 \\
\hline & \multicolumn{2}{|c|}{$6 n-61$} & \multicolumn{2}{|c|}{$61-7 m$} & \multicolumn{2}{|c|}{$7 m-7 d$} & \multicolumn{2}{|c|}{ Total } & & \\
\hline & $\mathbf{M}$ & S.D. & M & S.D. & M & S.D. & & & & \\
\hline \multirow{2}{*}{$\begin{array}{r}\mathrm{R} \\
\text { Upper } \\
\mathrm{L}\end{array}$} & 5.98 & 0.55 & 6.59 & 0.89 & 5.87 & 0.49 & \multirow{2}{*}{\multicolumn{2}{|c|}{113.26}} & & \\
\hline & 5.88 & 0.34 & 7.09 & 1.01 & 5.54 & 0.52 & & & & \\
\hline \multirow{2}{*}{$\begin{array}{r}\mathrm{R} \\
\text { Lower } \\
\mathrm{L}\end{array}$} & 5.35 & 0.64 & 7.59 & 0.99 & 5.24 & 0.69 & \multirow{2}{*}{\multicolumn{2}{|c|}{100.23}} & & \\
\hline & 5.26 & 0.56 & 7.90 & 1.13 & 5.07 & 0.56 & & & & \\
\hline
\end{tabular}

$(\mathrm{mm})$

Table 6. Means and Standard Deviations of Edge Cusp Spaces after Retention

\begin{tabular}{|c|c|c|c|c|c|c|c|c|c|c|}
\hline & \multicolumn{2}{|c|}{$1-1$} & \multicolumn{2}{|c|}{$1-2$} & \multicolumn{2}{|c|}{$2-3$} & \multicolumn{2}{|c|}{$3-5$} & \multicolumn{2}{|c|}{$5-6 n$} \\
\hline & M & S.D. & M & S.D. & M & S.D. & M & S.D. & M & S.D. \\
\hline \multirow{2}{*}{$\begin{array}{r}\mathrm{R} \\
\text { Upper } \\
\mathrm{L}\end{array}$} & \multirow{2}{*}{9.44} & \multirow{2}{*}{0.65} & 8.97 & 0.62 & 8.38 & 0.62 & 8.56 & 0.90 & 7.03 & 5.73 \\
\hline & & & 9.02 & 0.66 & 8.46 & 0.61 & 8.42 & 0.83 & 6.94 & 5.68 \\
\hline \multirow{4}{*}{$\begin{array}{r}\mathrm{R} \\
\text { Lower } \\
\mathrm{L}\end{array}$} & \multirow{2}{*}{6.06} & \multirow{2}{*}{0.45} & 6.42 & 0.56 & 7.02 & 0.47 & 7.96 & 0.66 & 7.30 & 0.76 \\
\hline & & & 6.52 & 0.44 & 7.14 & 0.43 & 7. 18 & 0.61 & 7. 49 & 0.72 \\
\hline & \multicolumn{2}{|c|}{$6 n-61$} & \multicolumn{2}{|c|}{$61-7 m$} & \multicolumn{2}{|c|}{$7 m-7 d$} & \multicolumn{2}{|c|}{ Total } & & \\
\hline & M & S.D. & M & S.D. & M & S.D. & & & & \\
\hline \multirow{2}{*}{$\begin{array}{r}\mathrm{R} \\
\text { Upper } \\
\mathrm{L}\end{array}$} & 5.73 & 0.57 & 6.68 & 0.78 & 5.55 & 0.62 & \multirow{2}{*}{\multicolumn{2}{|c|}{111.17}} & & \\
\hline & 5.68 & 0.49 & 6.97 & 0.92 & 5.34 & 0.56 & & & & \\
\hline \multirow{2}{*}{$\begin{array}{r}\mathrm{R} \\
\text { Lower } \\
\mathrm{L}\end{array}$} & 5.20 & 0.56 & 7.44 & 0.78 & 5.12 & 0.58 & \multirow{2}{*}{\multicolumn{2}{|c|}{98.80}} & & \\
\hline & 5. 10 & 0.42 & 7.74 & 1.00 & 5.11 & 0.50 & & & & \\
\hline
\end{tabular}


Table 7. Means and Standard Deviations of Overbite in Normal Subjects and Preoperative, Postoperative and after Retention Groups $(\%)$

\begin{tabular}{l|c|c}
\hline & M & S.D. \\
\hline Normal occlusal subjects & 31.92 & 9.24 (Kamata) \\
\hline Preoperative & 59.21 & 9.84 \\
Postoperative & 42.63 & 8.94 \\
After retention & 41.40 & 11.28 \\
\hline
\end{tabular}
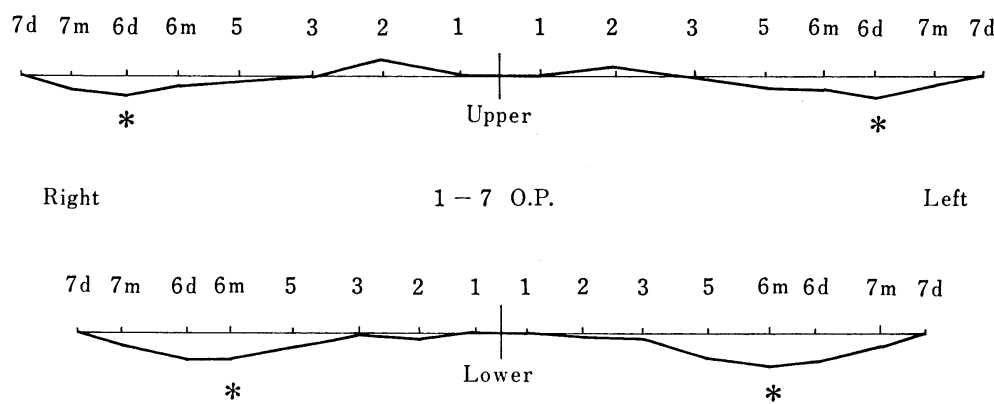

Fig. 3.
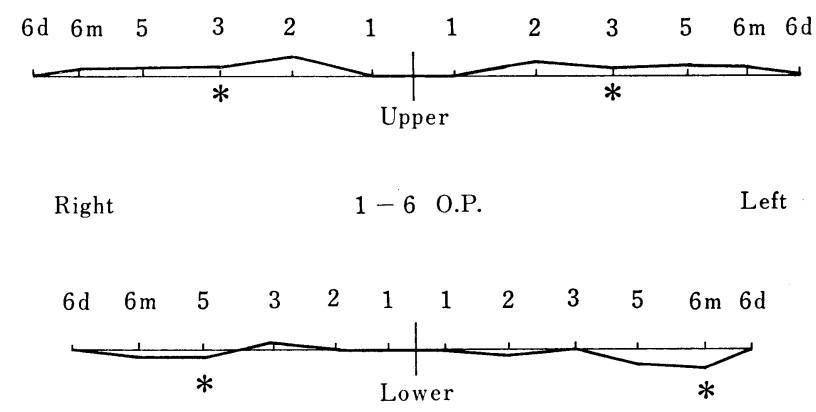

Fig. 4.
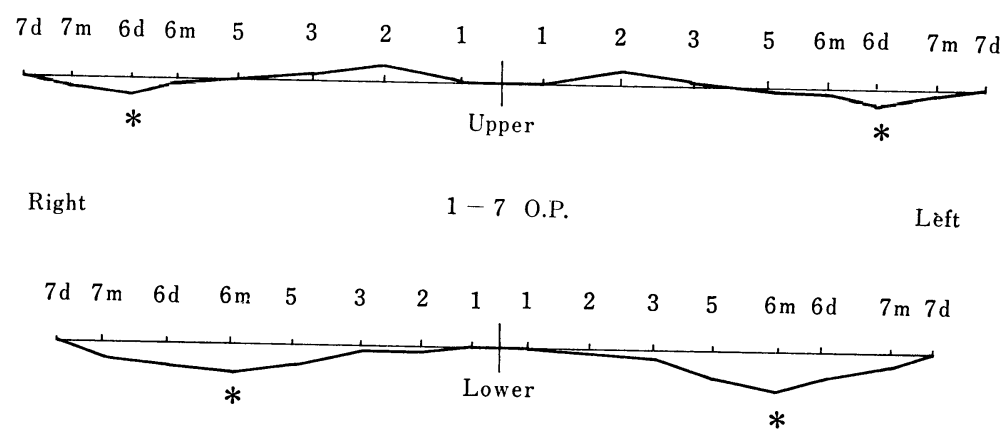

Fig. 5. 

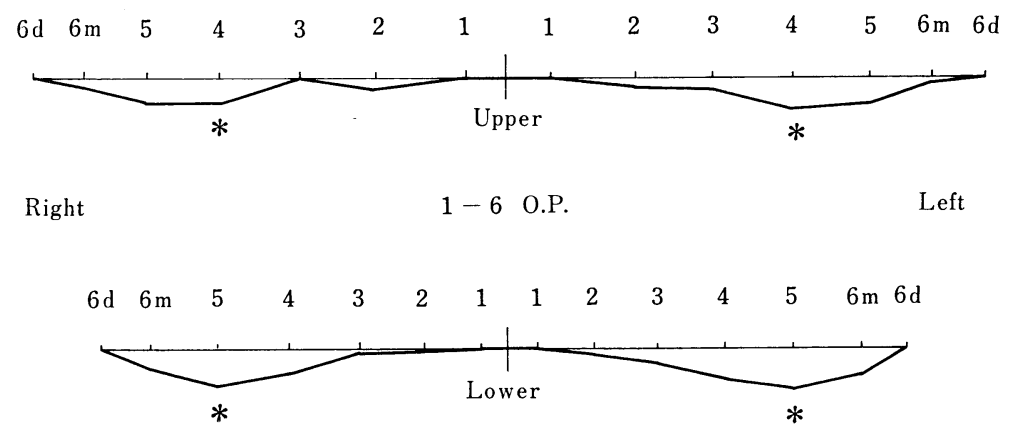

Fig. 6.

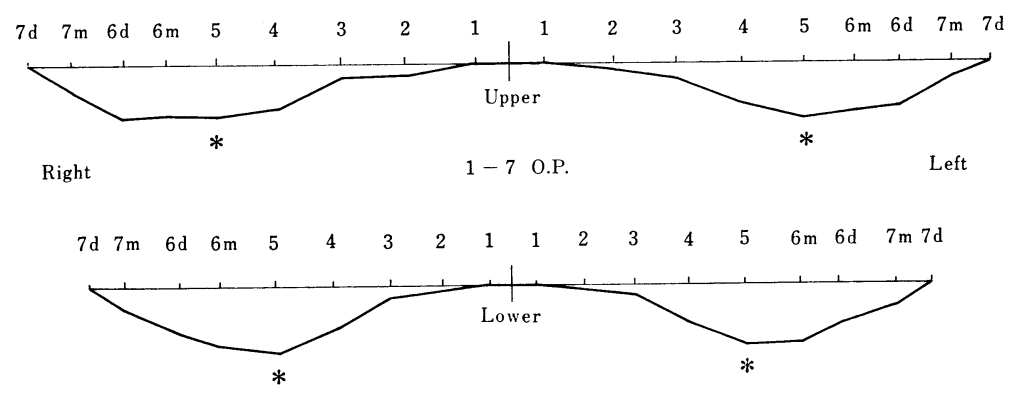

Fig. 7.
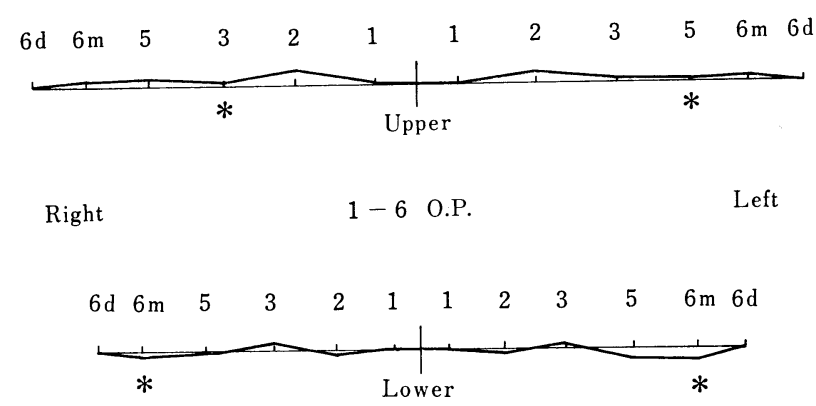

Fig. 8 .

2) The charts of curve of Spee prepared on the basis of these tables are given in Figure 3 to 8.

3) Statistical differences between the right and left after dynamic treatment and retention are given in Figures 9 and 10 (means). 

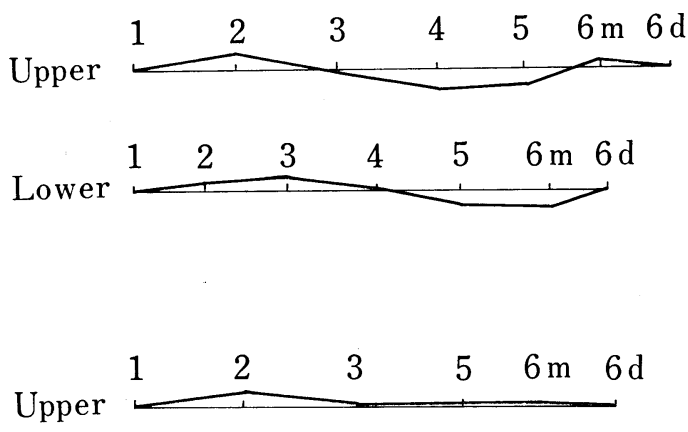

Lower $\begin{array}{rrrrr}1 & 2 & 3 & 5 & 6 \mathrm{~m}\end{array}$
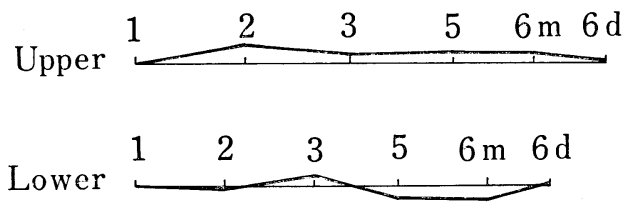

Fig. 9.
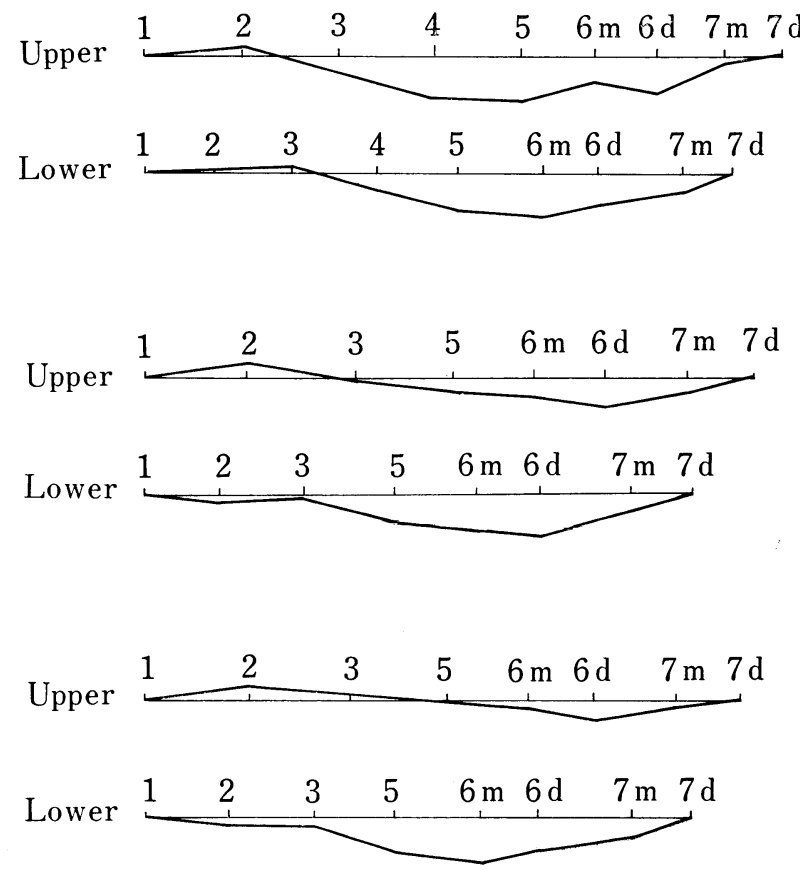

Fig. 10 . 


\section{Summary and Conclusions}

The present study dealt with the curves of Spee, respective incisal cusp ridge distances and degrees of overbite before and after a dynamic treatment as well as after retention of a selected number of orthodontic patients.

As a result, the following conclusions were arrived at:

1. On preoperative 1-6 o.p., the largest curves were observed with the maxillary right and left first premolars and with the mandibular right and left second premolars.

On 1-7 o.p., the deepest curves were observed with the right and left second premolars, the pattern being similar to the maxilla and mandible. The deepest curve at the second premolars is in agreement with the reports of previous investigators.

In some cases in whom the pronounced curves were formed, distal inclination of the maxillary first and second molars was noteworthy, being mesially positioned. Because of a pronounced mesial inclination of the mandibular together with premature loss of deciduous molars at the successional replacement period, enough space had not been provided for the second premolars which are much later in their eruption. For this reason, it is thought, the occlusal position tended to be lower.

2. On postoperative 1-6 o.p., a slight reverse mode resembling almost at raight line was observed with the maxilla, while a shallow curve was observed with the mandible.

On 1-7 o.p., on the other hand, a smooth and shallow curve was observed with the maxillary right and left first molars (disto-buccal cusps) and the mandibular right and left first molars (mesio-buccal cusps).

Since there was confirmed a tendency that the occlusal plane would become deeper after an orthodontic treatment, the treatment policy was adopted to render it either even or reverse at the finish.

3. On 1-6 o.p. after retention, a slight curve was observed similar to that of posttreatment cases with a somewhat noticeable trend, this fact being in common to the maxilla and mandible.

On 1-7 o.p. after retention, the findings were similar to those of postoperative cases but, as compared with the maxilla, the curve became somewhat deeper in the mandible.

It was not possible to establish definitely whether this deepening of curve in the mandible was due to relapse, natural result by reason of treatment or occlusal movement on the part of patients.

4. When the curve of Spee in normal occlusal subjects was compared with those of orthodontic patients both after dynamic treatment and retention, the latter were found to be either reverse or straight line. In the former, the curve was smooth and slight. Except for the lateral incisal region, the curve of Spee in the mandible was similar to that of normal occlusal subjects but with a tendency of being somewhat flat or even.

Similarly, on 1-7 o.p., the findings of postoperative and after retention curves were nearly the same, and this is particularly true of the mandible.

5. The degrees of overbite were $59.2 \%$ preoperatively, $42.6 \%$ postoperatively and $41.4 \%$ after retention. 
As shown by these changes, a reducing tendency took place in proportion to an improved occlusion.

6. The following values were measured regarding intervals or distances of the incisal cusp ridges.

Maxilla

Preoperative

Postoperative

After retention

Mandible

$131.8 \mathrm{~mm}$

$113.2 \mathrm{~mm}$

$199.2 \%$

$111.1 \mathrm{~mm}$

$115.4 \mathrm{~mm}$

$98.8 \mathrm{~mm}$

It may be inferred that these changes were brought about by the extraction of first premolars and closure adjustment of the band space. 